\title{
Nanogram Equivalents Per Liter
}

National Cancer Institute

\section{Source}

National Cancer Institute. Nanogram Equivalents Per Liter. NCI Thesaurus. Code C130192.

A concentration unit measured as a number of nanogram equivalent of solute per liter of solution. 